\title{
Detachment of empathy: a common denominator for two theories of humour
}

\author{
Ron Aharoni \\ Mathematics Department, Technion, Haifa, Israel \\ ra@tx.technion.ac.ilg
}

\begin{abstract}
This is a sequel to a previous paper (Aharoni 2018), in which I suggested that the game of humour is played not between two meanings of the same carrier, but between meaning and its carrier: the two are detached from each other by some means. In the present paper I want to substantiate this thesis by some evidence, the main one being referred to in the title of the paper. It is that two well-known theories of humour, both presently neglected to a large extent, are based on this mechanism. In both the carrier of meaning is not words, but actions. In fact, one of the main messages of the paper is that often the carrier of meaning in jokes, and in humour in general, are actions. I will try to show that both Bergson's "automatic behaviour" theory and the superiority (or derision) theory are based on detachment of empathy, namely of identification. Since, as I will try to show, empathy and identification are man's (and even animals') main tool in deciphering meanings of actions, this results in detaching actions from their meanings.
\end{abstract}

Keywords: empathy, meaning of actions, detachment of meaning, superiority, mechanical reaction.

\section{Introduction}

A problem worthy of attack

shows its worth by fighting back.

(Piet Hein, Danish mathematician and poet)

Few riddles in the history of thought have put up as vigorous a fight as the definition of humour. Two and a half millennia of research have produced little on which there is general consent. Most recent theories, at least the more popular ones, belong to the "incongruity" family. Such theories speak of collision of two modes of thought, or two interpretations of the same verbal expression, situation, or action. Incongruity has many formulations that are all akin in spirit. Hutcheson's (1750) "incongruity," Koestler's (1964) "bisociation," and the more recent "two scripts" theory by Raskin (1985) all speak about two modes of thought that meet at the same 
playground. An interpretation of some section of the world - be it words, situation, or actions is replaced by another or coexists alongside it.

However, there are two notable theories that do not belong to this family. Both drew a lot of attention in the past, testimony to the validity of the observations they incorporate. Yet, both are markedly less popular nowadays, for a good reason: their claim for universality is obviously off the mark. One is the oldest theory of humour, originating with Plato and Aristotle, that of derision. The other is Bergson's "automatic behaviour" (Bergson 1900), where a mechanical response occurs instead of the expected human, flexible reaction.

As noted, both theories validly point at types of humour that do exist. Ridicule is indeed funny, and automatic behaviour does make us laugh. Finding a common mechanism to the two may shed light on the mechanisms of humour in general.

\section{Main themes in the paper}

Here are the main ideas presented in the paper:

1. The basic mechanism in humour is not a play between two meanings, but between a meaning and its carrier. Specifically: a rift between the two, the detachment of a meaning from its carrier. This may involve switching to another meaning (in which case "incongruity" may apply), but not necessarily. There are cases where the essence of the detachment is that the carrier remains alone, bare of meaning.

2. "Detachment" means that the carrier acquires a life of its own. The usual state of affairs is that the carrier is servile to the meaning. It goes unnoticed, a transparent entity that only serves as a vehicle. We think through it, not of it. Detachment is victory of the carrier over the meaning, of the signifier over the signified.

3. Next to verbal expressions, the main carriers of meaning are actions.

4. The most common meanings of actions are intentions, motives, and drives. These are "meanings" in the sense that they are interpretation of the actions.

5. Meanings of actions play an important role in our life, because understanding intentions allows to predict the actions of the people and animals surrounding us.

6. Empathy, or identification, is the main tool in deciphering other people's intentions.

7. Bergson's (1900) "mechanicality" and derision both involve detachment of identification. The former, because we do not ascribe intentions to machines, and we do not identify with them. The latter, because derision means declaring the object to be worthless, devoid of intentions worth respecting.

8. Sometimes the humorous effect is generated by something that looks the converse of detachment - loading with meaning. Something that looks innocuous suddenly acquires an interesting meaning. Temporally, it is the opposite of detachment: the carrier starts as detached from meaning, and ends up as loaded with it. But appearance is deceptive: in fact, this is still detachment. It is detachment "in hindsight," which is not very different from "forward detachment ." Our brain goes very fast back and forth, and realises that a carrier that is now loaded was detached from its meaning before.

9. Implicitness, one of the joke's main weapons, is based on the loading of meaning.

10. Coincidences are funny because they constitute detachment of "intention" of the physical world, namely of causality. We start with ascribing meaning to the aggregation of seemingly related events, only to discover that there is no hidden causal link between them. 


\section{Meanings of actions}

"Meaning" is used in this paper in the sense of "interpretation." In one of its roles, it is what philosophers call "reference," namely a part of the world pointed at by the carrier of meaning. In another role, it can be some structure (pattern of behaviour) that lies behind an overt manifestation. For example, an intention guiding some overt action is the "meaning" of the action. In both cases, a structure $\mathrm{M}$ is associated with another, $\mathrm{C}$, where $\mathrm{C}$ (the carrier) is overt and on the surface, whereas $M$ (the meaning) is linked to it by way of interpretation. The interpretation can be a matter of convention, as in the case of common usage of words, while in other cases it may demand particular effort to unearth.

Words are the most obvious carriers of meaning. But they are far from being the only ones. Every interpretation of any part of the world establishes a "meaning." Situations have meanings: we assign interpretations, usually many of them, to any situation we encounter. But most importantly for the purpose of this paper-actions have meanings. Language acknowledges this: intending to do something is "meaning" to do it. We ask people for the meaning of their actions - what purpose they serve. There are many types of explanations for an action: drive, motive, aim, intention, wish, will. There are also hindsight meanings, like responsibility, judgement, or regret. All these are assigned in our minds to actions. Meanings of actions are crucial for our lives, because understanding motives and intentions of others enables predicting the direction the actions are taking. All this happens in our brains on a primeval, pre-verbal level. Animals, which do not have words at their disposal, depend for their survival on deciphering intentions. For this reason, humour based on play with meaning of actions is no less basic than verbal humour. In fact, probably much more. Only a small part of humour is purely verbal.

\section{Detachment of meaning of actions}

$\mathrm{X}$ throws a custard pie at $\mathrm{Y}, \mathrm{Y}$ bends over and the pie hits $\mathrm{Z}$. What makes this funny is the split between intention and outcome. When a person wears glasses that deflect light, and tries to touch something, we laugh at his failure because the result of his action is detached from his intention. These are not cases of "change of meaning," since the "meaning," the intention, has not changed. It is just that the carrier of the meaning - in this case the action (being a carrier of meaning because we ascribe an intention to it) - assumes a life of its own. It is no longer associated with the intention. This dissociation is "detachment." Here is another example of "pure" detachment, in which no new meaning appears.

1. Two labourers toil on a mountain. One digs a hole in the ground, the other fills it, one digs, the other fills. An onlooker is puzzled - "What are you doing?" "Usually we are three," explains the digger. "I dig, Sasha plants a tree, and Misha refills. Today Sasha is sick."

The act of digging is severed from its goal - the planting. The digging does not gain a new meaning - it only loses its old one.

As already noted, intention is not the only possible meaning of actions, and is not the only type of meaning detached in humour. For example, an action can be detached from its drive: 
2. A woman returns to her room in the old age home to find another old lady with her hand on her husband's pants. She is furious: "What does she have that I don't?" "Parkinson," answers the husband.

An action presumably loaded with meaning turns out to be involuntary convulsions. Here is detachment of motive:

3. A guy walks into a bar and orders the barman - "A drink for me, a drink for you, drinks all around." The barman serves out the drinks but when asked to settle the bill, the generous customer declares that he hasn't got a penny. The angry barman gives him a good thrashing and kicks him out. The following week the same guy appears, and orders again - "A drink for me, a drink for you, drinks all around." Certain that the customer has learnt his lesson, the barman complies. But again, when it's time to pay, the customer declares he has no money. Once again, the barman beats him up and throws him out. The following week the same guy appears: "A drink for me, drinks all around," he orders. The barman is offended: "What about me?" "You," says the customer, "when you drink you become violent."

The generous-at-others'-expense nonchalantly construes the behaviour of the barman to his convenience, detaching it from its real motive.

The following children's joke, endearing in its absurdity, is a good example for detachment of an action from its intention.

4. A scuba diver with the best diving equipment tries his best to dive, and fails. Suddenly, going past him towards the bottom of the sea, he sees a man with no equipment at all. "How do you dive so well?" asks the scuba diver. "I am not diving," answers the man, "I am drowning."

The diving, which seems meaningful (namely intent), turns out to be inadvertent. In the context of this paper, this means that it lost its meaning - the intention.

5. Two old ladies ride in a car. To the amazement of the woman sitting in the passenger's seat, the car goes through red light. She keeps quiet, but then this happens a second time. When the same occurs a third time, she says to her friend - "excuse me, but do you know that you just went through red lights three times?" - "What?," answers her friend, "am I the driver?"

The driving turns out to be detached from intentions, or even awareness of responsibility.

6. First old man: "Do you remember how we used to chase girls?" Second old man: "Yes. But I don't remember why."

Chasing girls is summarily detached from its drive.

7. What is the Englishman's grace? - "Please, God, give me strength to eat this meal in front of me."

As if he has no control over the quality of the food - pure detachment of responsibility. Here is another detachment of responsibility, this time for the choice of a spouse:

8. A man stands before a grave in a cemetery, and laments "Why did you die, oh why did you have to die?" A passer-by is intrigued: "Was he a relative?" - "No," says the man. 
"A friend?" "No, never met the guy." "So why are you so sad?" "He was my wife's first husband."

Again, any interpretation in terms of two modes of thought will be coerced. You may offer "mourner vs. second husband," but this will miss the point - detachment of responsibility. As if it is only the death of the former husband that led to the marriage.

\section{Some examples of detachment of words from their meaning}

Here are a few examples of detachment of words from their meaning, that is "pure" in the sense that there is no switch of meaning. Instead, the words referred to in the joke become empty.

9. How do you know that a salesman is cheating? - His lips are moving.

The movement of the lips replaces the meaning, in this case the interpretation of the words: you do not have to understand the words to recognise the lie. The work of interpretation and understanding of the words become redundant. Something similar happens in the following. Meaning is replaced by mode of speech:

10. American: Lincoln never uttered a lie from his mouth.

Englishman: Of course. He spoke through his nose, like all of you.

The following dictum, whose origin I have not been able to trace, is humorous, but contains a grain of truth. It detaches words from their meaning.

11. What is the difference between mathematics and philosophy? In mathematics somebody important is somebody who said something important. In philosophy something important is something said by somebody important.

The meaning is replaced by something external to it - the identity of the owner of the saying.

Sometimes a switch of scripts does exist, but it is not the crucial element.

12. A man comes for confession, and says: "I am 80 years old, and yesterday I met two beautiful 18 years old girls, and o-ho, what we did all night." "Say two Hale Mary's and you will be forgiven," says the minister. "But I am Jewish!" says the man. "So why did you tell me?" - "I am telling everybody!"

"Telling" is victorious over "doing." The bragging earns priority over the deed. Symbol over meaning.

\section{Loading with meaning, and the joke's indifference to temporal direction}

"Detachment of meaning" may sound like a strange definition for humour. Aren't many jokes based on precisely the opposite? Something acquires a new, unexpected meaning. The expression or the action are then not detached from their old meaning, but on the contrary - they connect to a new one. They are suddenly loaded with meaning. Here are two jokes illustrating this. In the first joke the words initially serve merely as reference. Suddenly, they acquire meaning. 
13. Three men, called Stupid, Nobody and Nothing, go on a fishing trip. Suddenly Nobody falls into the water, and Nothing asks Stupid to phone the police. Stupid calls: "Hello, I am Stupid. I am calling for Nothing. Nobody fell into the water."

At first hearing, the names sound silly and inane. We assume that their conventional meaning will not be used. But then the meaning emerges and becomes important. In the following joke, it is an action that gains a new meaning, in this case intention:

14. A woman disappears. Her husband looks for her everywhere, informs the police, all to no avail. Two days later, she appears at home. "What happened?" asks the husband. "Don't ask," she says. "Five brutes abducted me and made me their sex slave for a week." "A week?" wonders the husband, "But you have only been away for two days!" "No," she says. "I just came to pick up a few things."

Naturally, the loading with meaning involves a switch of interpretation, as exemplified by the last two jokes. But not any switch is funny. It is the loading with meaning that generates the funniness. Here is another example of loading with intention.

15. "Whe-whe-whe-re-i-i-i-is the s-s-s-chool fo-fo-fo-for stammerers?"

"You don't need it. You stammer very well."

The main point is loading the stammering with meaning - intention. It becomes an aim, not an involuntary act.

16. "What is ten lawyers at the bottom of the sea?"
"A good start."

The question sounds like a logical riddle. The answer loads it with a new meaning, a wish.

So, detachment or loading? The answer is that, in spite of looking the reverse of each other, they are the same. At their core, there is the same mechanism. Consider the "stupidnothing-nobody" joke. At its end, we look back and realise that the names were detached from meaning when we first heard them (we chose to ignore the meaning). Our brain is very fast, faster than we think it is, and it quickly scans events in both directions of time. When meaning is loaded, we look back and realise that before it had been detached. This is "hindsight detachment." In this respect, jokes are indifferent to temporal direction. Whether the detachment occurs in hindsight view or in the forward direction of time is immaterial. Here is another example:

17. Pete and Repeat went for a swim. Pete drowned. Who remained? - Repeat. OK, Pete and Repeat went for a swim. Pete drowned. Who remained?

In the beginning of this joke the word repeat is a seemingly meaningless name. At its end, it acquires meaning.

Implicitness, one of the joke's strongest and common techniques, is nothing more than loading with meaning. It consists of loading a new and interesting meaning onto a seemingly innocuous expression.

\section{Derision}

The first theories of humour ever proposed were probably those of Plato and his disciple Aristotle. As already mentioned, both the master and the student gave the same answer: derision. 
Every laughter is a leer at the misfortunes or shortcomings of others. Here is a description of this theory in Zillman (1983: 86):

In Philebus, through the dialogue between Socrates and Protarchus, Plato developed a classification for the ludicrous. Essentially, he suggested that the exhibition of ignorancebased vain conceit of beauty, wisdom, or wealth by friends constitutes the ludicrous and ought to be met with laughter - or perhaps more appropriately, punished by laughter.

This is not very complimentary, and indeed Plato denounced humour and recommended graveness. Laughter may end up in disrespect for the gods - Gods forbid.

The theory obviously carries some truth. Scorn always has a humorous tinge. Derision is accompanied by joy, sometimes even laughter. "Ridicule" comes from the Latin ridere, "to laugh" and is described as "laughing at." For instance, the children who, in the biblical story (Kings 2, 2:23-25) mocked the prophet Elisha - "go up baldy, go up baldy" - were gleeful, at least in the first part of the story. (They were later punished by two bears, who devoured fortytwo of them). Arthur Koestler (1964) counts 29 references to laughter in the Bible, 27 of which are in the context of scorn.

Yet clearly, only a small part of humour is based on derision. In most jokes - in particular those based on incongruity - one must bend over backwards to detect mockery. Strangely enough, somebody performed this feat. Thomas Hobbes (1650) maintained that laughing at a joke derives from self-mockery. "How naive we were," we tell ourselves, "to have fallen for it." There are supporters of the derision-superiority theory to this day. Extensive literature surveys on the topic abound (see Gruner 1999). But it is not widely popular nowadays, suffering from the curse that lurks for all humour theories: over-generalisation.

\section{Mechanicality}

Bergson's Creative Evolution (Bergson 1907), that won him eventually the Nobel prize, promotes an idea that preoccupied him throughout his career, that of the "force of life," or "élan vital." It speaks about the advantage of man over machine. Man creates himself, so claimed Bergson. He is not subject to mechanical laws. It is in light of this idea that we should read his theory of humour, propounded in Laughter (Bergson 1900). In this short book he claimed that we laugh when we detect automatic behaviour where a human behaviour is expected. Namely, when the élan vital has a day off, and a person behaves like a machine.

This is clearly over-generalization, but on the other hand the idea does carry some truth. Every theory of humour must address the best known of all comic incidents - slipping on a banana peel. Why is it funny? As mentioned above, Plato and Aristotle opted for the natural, and (too) easy answer: Schadenfreude. Gloating over the person's mishap. Bergson too, used tumbling (he does not mention the banana peel, but let me use it here) as the starting point of his theory. His explanation is that we laugh because the person behaved like an automaton. It is victory of matter over mind. The will of the banana peel prevailed.

Bergson's theory successfully explains other forms of humour as well. For example, comedies of character. The protagonists of such comedies (the hypochondriac, the miser, the distracted) do not act according to their free will. Observing them, we do not identify with their will, but ascribe their behaviour to their declared traits. They are marionettes of their labels. Bergson's explanation is beautiful indeed: the person does not act by his/her will. They are governed by the stereotype, being slaves of their image. It is the ethnic origin, or some other stereotype, that is performing the action, not the person. 
Another instance of humour illuminated by this interpretation is the comicality of repeated occurrences. If, walking in the street, three people come across you, clearly unrelated to each other, all wearing green trousers and yellow shirts, you will find it funny. Coincidences are always funny. Why? - Automatism, says Bergson. Stiffness of behaviour of the world. Schuetze (1817), a precursor of Bergson in linking mechanicality and humour, gives the example of a stream of people going out of the same door - they appear comic, he says, since they remind us of a wheel turned by water. In Section 12, we shall relate to the funniness of coincidences, in terms of detachment of meaning.

No doubt, automatic behaviour is often funny. A living creature that behaves like a robot, and does not change its behaviour with changing circumstances, makes us laugh. Cartoons take such a situation to absurdity in the well-known scene of the protagonist continuing to tread in air after the ground has disappeared beneath his feet. The automatic behaviour continues, though circumstances have changed.

Let me mention here a link to an idea mentioned above - loading with meaning. Many have noted that not only man behaving like a machine, but also a machine or an animal behaving like a human, are funny. A dog dressed for Halloween makes us laugh. In a Gary Larson cartoon, a dog puts up a sign that says "Cat Fud," pointing at the washing machine, and prays that the cat will be deceived. Many jokes are based on animals behaving like humans, and all these are loading the actions of animals or machines with meanings - human intentions.

As already noted, Bergson's explanation fits only a small section of humour. But the grain of truth it contains will be useful for us. It points at a head of a trail leading to interesting places.

\section{Detachment of empathy}

Derision and automatic behaviour look very far apart. Is it possible that they have something in common? They must, if we believe (as I do) that all manifestations of humour have some common mechanism. Indeed, there is a basic mechanism that the two share. Let me start with the obvious: both involve de-humanisation. The person observed is deprived of human motives. In mechanical behaviour, because machines do not possess human intentions or intelligent planning. In scorn, because the derided person seems to be so stupid, or worthless, that we do not take his/her intentions seriously. He or she loses their status as human beings having wishes, intentions and will. They are degraded to inanimate status.

The concept most pertinent to this is empathy. In scorn and in ascribing mechanical behaviour, empathy with the person is detached. In other words, we withdraw our identification. Scorn is the precise opposite of empathy. We reject the person, an attitude that manifests itself in the facial expression: an imitation of spitting food out, and pulling the nostrils as if to avoid bad smell. The person is perceived as hollow, devoid of intentions and emotions. Perception of mechanical behaviour also results in detachment of empathy, for a different reason: we do not empathise, or identify, with machines. Our empathy goes to humans and animals. Having discovered automatism in a person's behaviour, we stop identifying with him, because his actions are not guided by will, and empathy means identification with intentions and will. Mechanical behaviour means, for us, actions devoid of motives, intentions, aims - all that makes us human.

Surprisingly, we invest a lot of energy into detachment of empathy. Which, in turn, must mean that empathy is significant. This is indeed the case. Empathy is highly valued by its receiver, and justly so: it means compassion and understanding. But in fact, it is more important for the giver. It is much more than being nice to our fellow human beings: it enables predicting 
their actions. Identifying with a person is the king's road to understanding him/her, and knowing where they are heading. This, of course, is essential for survival.

Such an advantage must express itself genetically, and indeed evolution has shown its esteem for empathy by imprinting it in our genes. In fact, not only in the human genes but in the genes of all primates. We do not have to learn empathy (at least, most of us don't) - we are born with it. Some forty years ago, it was discovered that the brains of primates contain so-called "mirror neurons," that operate (mutedly, namely shooting signals without causing action) when their owner observes others performing some specific action (Rizzolatti \& Craighero 2004). These are "empathy neurons."

When we identify with a person's actions, we want and intend and plan together with $\mathrm{him} / \mathrm{her}$. Sport events are attractive for us because they provide opportunity to desire something - success, being loved and admired - vicariously. But there is no point in identifying with a person slipping over a banana peel, because his/her action is not governed by his or her intentions. They wanted to move forward, and the peel wanted otherwise. When we realise that the action is detached from will, the identification vanishes. The action is perceived as hollowed of motives.

This is the reason that, while in tragedies we identify with the protagonist, and undergo a psychological process similar to his/hers, in comedies we are dissociated from the characters. We laugh at them, not with them. The main element in comedies is that the protagonists are not in full control of their actions. They are fallible, and what they want does not materialise. Drama is based on accentuation of the meanings of actions: the protagonists are in deep love, or mortal danger. We go along with them, imagining ourselves in their shoes. Comedies, by contrast, are based on failures of actions to have meanings: not taking the intentions of the protagonists seriously means not identifying with them. We feel detached, often superior. The saying "comedy is tragedy plus time" means precisely this: temporal distance generates distance in identification and in involvement.

"Detachment of intentions" can explain a riddle that arises with respect to the Bergsonian theory: that there are actions that look mechanical, and yet are not funny. For example, a parade. The soldiers behave mechanically, and still we do not laugh. The reason is that the soldiers' action is not detached from their will. Their will is subjugated to orders, but it is there. The same is true for workers who act as if mechanically. In Chaplin's "Modern Times" (a pure illustration to Bergson's theory) we laugh at the mechanicality of the hero. His job is to turn two screws on a fast-moving conveyor belt, all day long, until mechanicality takes over: he is trying to turn the screws on everything he sees. The reason that this is funny, while watching a real worker on a conveyor belt is not, is that Chaplin gives us clues that his "work" is not for real, and so the empathy is detached.

\section{An example combining derision with mechanical behaviour}

Treating a person as inanimate is sometimes a means for degrading him. So, the two - derision and relating to a person as if $\mathrm{s} / \mathrm{he}$ is a machine, sometimes concur. A nice example is given in Tsakona (2017: 187). The purpose of her paper is to examine how the general public perceives humour, via their reactions to a humorous ad on TV. A mobile phone's seller promises that, if not satisfied, customers could return the phone with no penalty. The metaphorical situation they gave in the ad was that of a man returning his wife to her mother:

18. $\mathrm{M}(\mathrm{an})$ : Wha:::::t's that? \{ironically to his wife who brings okras to the table\}

W(oman): Okras! \{with enthusiasm\}

M: Okras! \{with fake enthusiasm\} Okras again. \{Sound signalling that the 
man starts fantasizing \} Get up! Get up you! \{in an angry tone \}

\{We watch the couple go to her mother's house and knock at the door.

The husband's mother-in-law opens the door, happy to see them.

Mother-in-law: Wel[come]

M: [A::::]haha:: So dear mother-in-law do you see her? Well, I am bringing

her back [exactly] as I took her [from you]. Untouched, unworn, and in her

packaging.

\{The mother-in-law looks surprised.

M: She has cost me 650 coffees, 152 meals, 1 birthday present and 2 nameday

ones, Maria dear \{he addresses his wife\}, can you tell me, did we watch

it together that great movie "Love in Swaziland"? \{his wife nods positively\}

Well, plus 39 movie tickets.

\{Sound signalling that the man's fantasy is over.\}

W: Okras! \{with enthusiasm\}

M: Uh? \{waking up from the fantasy\}

W: Like my mum cooks them.

M: U:::::hhhh

The comments arriving from the public were, of course, that this is degrading for the wife and for women in general (see Tsakona 2017). The devaluation is done via one main vehicle: equating a human being to a mobile phone. Treating the wife as an object, devoid of human will.

\section{Detachment of spontaneity}

Bergson mentions "momentary freezing of feelings" as one type of mechanicality. This is almost synonymous with detachment of spontaneity. A gap appears between will and action, and the person behaves, at least momentarily, as if not driven by inner will. For example, the famous question of the children who, on a day of outing, ask their parents: "Are we having fun yet?" This is "automatic behaviour" in the sense that it is detachment of emotions, which are presumed here to come from the outside.

Old age is an excellent vehicle for detachment of spontaneity, and of drives in general:

19. Wife: "Do you remember how, when we were young, you used to nibble gently on my earlobe?"

Husband: "If you bring me my glasses and my false teeth, I can do it again."

Bodily expressions are usually spontaneous, and not subject to conscious control. Here is what happens when an expression is postponed:
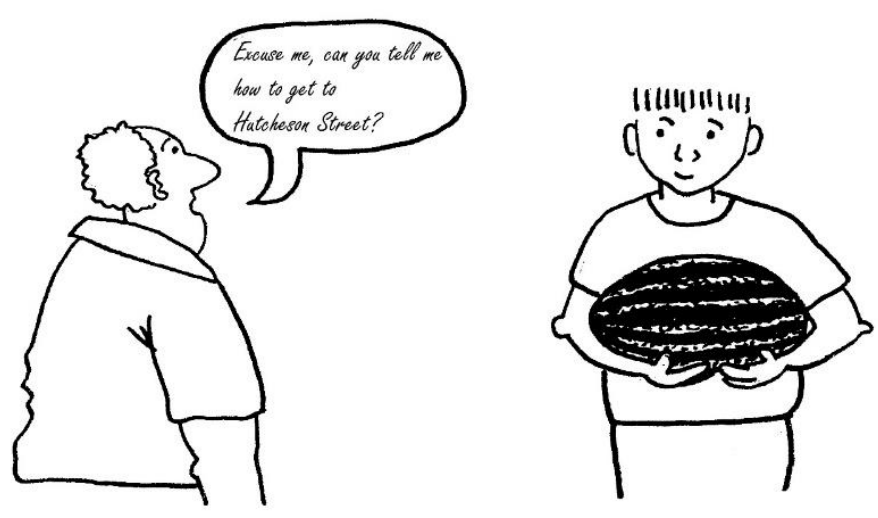

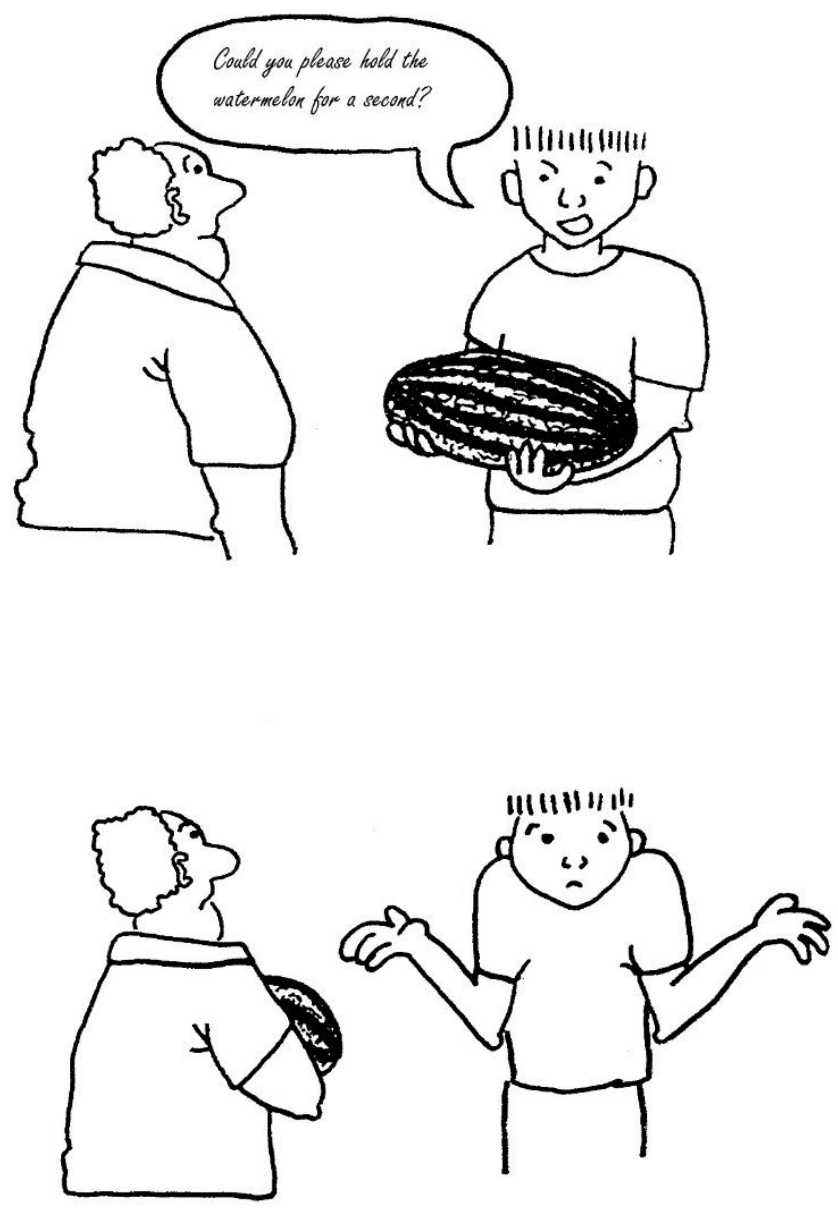

Figure.1 Bodily expressions (Copyrights on the drawings were kindly permitted by M. Aharoni)

An expression that is supposed to be spontaneous and automatic turns out to be consciously controlled, thereby losing the vivacity we usually ascribe it.

20. In the TV series "Modern family," a woman is angry with her husband. "I could have slapped you," she tells him, turns around and walks away. After a second or two she returns and says "As a matter of fact -" and slaps him on his face.

What is funny here (the hired audience, at least, laughed) is the detachment of the slap from immediate anger.

\section{Coincidences and detachment of causality}

The Bergsonian explanation for the funniness of coincidences was discussed in Section 8 . Bergson (1900: Chapter 1) quotes a remark of Pascal: "Two faces that are alike, although neither of them excites laughter by itself, make us laugh when together, on account of their likeness." Bergson's explanation, "repetition," namely automatism of nature, is indeed apt. But even more illuminating is "detachment of intentions." This time, intentions of nature, by which I simply 
mean causality. A causal explanation of events is similar to explanation of human acts in terms of "intentions" and "motives." Both are hidden forces behind overt events. In coincidences we realise that there is actually no real causal link, so the events are detached from these forces.

\section{Conclusion: Why detach?}

The idea of "detachment of meaning" may sound strange. What does the detachment attain? Having worked so hard in generating meanings, why should we dismantle them? The answer is that detachment achieves the so much coveted process of change. To make change possible, you must first detach old fixations. Humour enables us precisely this. It allows us to be sceptical, to raise the possibility that things are not what they appear to be. This is what cynical perception of human actions is about: taking people's motives with a grain of salt. Indeed, cynicism has its humorous taint. Satire, which also has humorous flavour, does precisely this: it undermines pretensions. Which brings us back to Plato's derision theory. As mentioned above, in Philebus (Plato 1987), he claims that we laugh at people's ignorance about themselves. We laugh at people who think of themselves as wealthier, better-looking, more virtuous, or wiser than they really are. Ordinarily, we identify with people's actions and their self-perception. In humour we detach from the identification, perceiving things more objectively.

Scepticism towards other people's motives is useful, but even more so is detachment of self-perception, casting in doubt our own intentions and motives. We protect ourselves with an image we project to the world. This is our self-image, which is precious to us, and hard to break or change. Humour is a gentle way of doing this.

This I conceive to be the chemical function of humour: To change the character of our thought.

(Lin Yutang, American-Chinese writer, Famousquotes 2018)

\section{References}

Aharoni, R. (2018). 'From meaning to carrier - a common denominator for three strains of Humour', The European Journal of Humour Research 6:3, 13-29.

Aristotle. (1895). Poetics. New York: Macmillan.

Bergson, H. (1900), Laughter: An Essay on the Meaning of the Comic. New York: Macmillan. Bergson, H. (1907), 'Creative evolution,' English version: (1911) tr. Arthur Mitchell, Henry Holt and Company, NY.

Bible.org, https://bible.org/seriespage/4-elisha-and-two-bears-2-kings-223-25.

Famousquotes, http://famousquotefrom.com/lin-yutang/

Gruner, C. R. (1999), The Game of Humour: A Comprehensive Theory of Why We Laugh, Transaction Publishers.

Hobbes, T. (1650). Human Nature. Reprinted in (Morreall, 1987).

Hutcheson, F. (1750), Reflections Upon Laughter, and Remarks on the Fable of the Bees, Glasgow: R. Urie.

Koestler, A. (1964). The Act of Creation. Penguin Books, New York.

Morreall, J. (ed.) (1987). The Philosophy of Laughter and Humour. Albany: NY, State Univ. Press. 
Morreall, J. (2008). 'Philosophy and religion', in A Primer of Humour Research, Victor Raskin, ed., Berlin: Mouton de Gruyter.

Plato. Philebus. Reprinted in (Morreal, 1987).

Raskin V. (1985). Semantic Mechanisms of Humour. Dordrecht: D. Reidel.

Rizzolatti, G. \& Craighero, L. (2004). 'The mirror-neuron system.' Annual Review of Neuroscience (27) pp. 169-192.

Tsakona, V. (2017), 'Humour research and humour reception: Far away, so close', in Humorous Discourse, Chlopicki, W. Brzozowska, D., (eds.) Berlin: Mouton De Gruyter, pp. 179-201. 